\title{
ARTIGOS
}

\section{HEGEL E O JOVEM LUKÁCS: DA CONSONÂNCIA ESTÉTICA À DISSONÂNCIA POLÍTICA}

Antônio Vieira da Silva Filho* antoniovieira@unilab.edu.br

RESUMO Este trabalho desenvolve a concordância estética e a diferença política entre Hegel e o jovem Lukács da "Teoria do romance". O jovem autor húngaro se apropria da estrutura conceitual da "Estética" de Hegel, pois entende as formas poéticas em sua relação com o desenvolvimento do conteúdo histórico. Lukács e Hegel concebem, desse modo, as duas formas da grande épica (epopeia e romance) em estreita conexão com o momento histórico que as fundamenta: a Grécia arcaica configurada por Homero e a experiência da fragmentação e da consolidação da subjetividade lírica que a modernidade traz consigo. Não obstante a assunção da herança estética de Hegel, o jovem Lukács se afasta das conclusões positivas de Hegel acerca da modernidade, a saber: da suspensão da liberdade fragmentada e lírica da sociedade civil burguesa pela liberdade objetiva na unidade e totalidade da forma Estado, unidade e totalidade verdadeiramente apreendidas pela forma filosófica. Lukács, ao contrário de Hegel, entende a modernidade a partir do ponto de partida negativo, isto é, não a vê como a consumação da liberdade do homem, mas a compreende como a experiência do sujeito fragmentado $e$ separado das estruturas sociais.

Palavras-chave "Teoria do romance", lírica, romance, Estado, sociedade civil burguesa, jovem Lukács, Hegel. 
ABSTRACT This work develops the aesthetic agreement and the political difference between Hegel and the young Lukács, who wrote the "Theory of the Novel". The young Hungarian author appropriates the conceptual structure of the Hegel's "Aesthetics", because he understands the poetic forms in their relation with the development of historical content. Lukács and Hegel thereby conceive the two forms of the great epic (Greek epic poem and novel) in close connection with the historical moment in which they arise: the archaic Greece configured by Homer and the experience of fragmentation and consolidation of the lyrical subjectivity brought by modernity itself. Despite the assumption of Hegel's aesthetic heritage, the young Lukács departs from Hegel's positive conclusions about modernity, namely: from the suspension of the fragmented and lyrical liberty of the bourgeois civil society by the objective freedom in the unity and totality of the State form, unity and totality truly seized by the philosophical form. Lukács, in opposition to Hegel, understands modernity from the negative starting point, that is, he does not understand it as the consumation of human freedom, but as the experience of the human subject fragmented and separated from the social structures.

Keywords: "Theory of the Novel", lyrics, novel, State, bourgeois civil society, young Lukács, Hegel.

No $§ 257$ da "Filosofia do direito", Hegel define, na economia interna de seu sistema filosófico, o que é o Estado e a perfeita consonância desta instituição com a sua época. Hegel concebe a experiência moderna como aquela na qual a figura do Estado se apresenta como a "realidade efetiva da ideia ética", ${ }^{1}$ na qual a liberdade do homem cumpre o desenvolvimento de todos os seus lados, isto é, como uma formação histórica na qual a liberdade se realiza pela primeira vez como particularidade (Besonderheit), na esfera da economia, ao mesmo tempo que se realiza objetivamente, em seu acordo como cidadão, no fim político universal do Estado. ${ }^{2}$

Tal imagem da vida moderna considera que a esfera mais ampla do Estado é capaz de corrigir o privatismo da sociedade civil burguesa. Hegel afirma, ao mesmo tempo, a capacidade do Estado moderno de comportar ou 
acatar o desenvolvimento da particularidade. É essa imagem que se encontra no centro da tese hegeliana de uma superação da arte pela filosofia, bem como da específica diferença entre a epopeia e a épica moderna, todas temáticas ponderadas com fundamento nessa compreensão da culminância da liberdade do espírito na modernidade.

A estrutura triádica da sociedade moderna, conforme Hegel, torna-se demasiadamente mediada para a apreensão e exposição artística. A assertiva hegeliana, na "Filosofia do direito", de que a modernidade é a época que faz jus ao conceito, explicita a identidade que há entre a mediada sociedade moderna e a sua forma verdadeira de exposição, a filosofia. Diz ele que "a criação da sociedade civil pertence, de resto, ao mundo moderno, que, pela primeira vez, faz justiça a todas as determinações da Ideia". ${ }^{3}$ A arte, que outrora, na experiência grega, ainda era capaz de apresentar a verdade, tornase na modernidade um problema, pois não está apta a apreender e apresentar a totalidade da experiência mais desenvolvida da liberdade, aquela que se apresenta agora por meio do desenvolvimento histórico da particularidade na esfera da sociedade civil burguesa.

A impossibilidade da arte de expor a liberdade moderna é determinada pelo caráter imediato da arte, isto é, pelo fato de a atividade artística apresentar a verdade numa unidade imediata sensível entre o universal e o particular. Esse caráter imediato da exposição artística a impossibilita de desenvolver adequadamente as diversas contradições que aparecem quando a particularidade entra na cena histórica, pois a arte não comporta a exposição das muitas mediações, agora, necessárias à exposição da totalidade. As contradições apresentadas pelo desenvolvimento da particularidade, embora desenvolvidas no interior de uma totalidade objetiva, a do mundo moderno, apenas se apresentam artisticamente sob o ponto de vista do sujeito, do indivíduo portador de tais contradições, ponto de vista fragmentário e contraposto à totalidade objetiva. Em razão disso, a arte se converte, segundo a concepção hegeliana, numa forma expositiva que se restringe ao âmbito da própria particularidade, isto é, ela não pode mais expor a totalidade social, mas apenas o fragmentado mundo das particularidades subjetivas. ${ }^{4}$

O caráter verdadeiro da arte como um todo e também da poesia é a exposição da unidade imediata entre particular e universal. Na modernidade, todavia, essa relação se torna problemática, pois a subjetividade formadora não se encontra mais em unidade imediata com o universal ético. Isto significa 
que o próprio artista desenvolve conteúdos cada vez mais particulares, que assim já não comportam, imediatamente, o substancial da vida ética. Estes conteúdos particulares, todavia, o ânimo, o sentimento, tudo aquilo que diz da vida interior subjetiva do poeta, somente pode se apresentar universalmente por meio da reflexão, pela qual os conteúdos em si particulares podem aparecer universalmente. Mesmo a universalidade que resulta da reflexão do artista, para Hegel, não diz do que é verdadeiro no sentido da objetividade da vida ética, mas apenas universaliza os conteúdos da própria subjetividade que todo sujeito moderno pode, em alguma medida, compartilhar.

É por isso que, para Hegel, em tal contexto histórico, a arte aparece apenas como momento subordinado, como exposição da particularidade, dada a incapacidade da subjetividade formadora em apreender e apresentar a totalidade também do ponto de vista da sua objetividade. Quando a subjetividade se torna autônoma em relação ao todo, a arte deve se apresentar na forma da unilateralidade, da sua separação em relação à substancialidade e totalidade efetivas.

$\mathrm{Na}$ "Filosofia do direito", Hegel apresenta o aparecimento histórico da sociedade civil burguesa como aquele que coincide com a autonomia formal da subjetividade. A liberdade dos indivíduos na esfera da sociedade civil burguesa é apresentada como ainda formal porque o que eles perseguem na satisfação das carências é apenas um fim particular. Diz-nos Hegel que "esta libertação é formal (formell), visto que a particularidade (Besonderheit) de fins continua sendo o conteúdo que lhe serve de fundamento". Esta particularidade da liberdade, o egoísmo do homem na sociedade civil burguesa, é ultrapassada na esfera da liberdade universal do Estado. No final da "Filosofia da História", Hegel afirma sobre a necessidade dessa superação, porque somente no Estado o homem alcança "a liberdade objetiva, as leis da liberdade real [do Estado, que] exigem a submissão da vontade contingente; pois esta é sempre formal (formell)". 6

$\mathrm{Na}$ "Estética", Hegel explica o que significa a liberdade formal na forma de arte romântica quando acentua que o espírito se retira da exterioridade e se centra em si mesmo. A matéria romântica do círculo religioso, como a primeira forma de exposição da arte romântica, os aspectos exteriores da aparição de Cristo: vida, morte, os discípulos, ressurreição etc., são ultrapassados e superados pelo retorno do espírito para o interior do homem. Afirma Hegel que, nesse momento da forma de arte romântica, "é o mundo do particular 
(Welt des Bensonderen), do existente em geral, que se torna livre para si e, na medida em que não aparece penetrado pela religião e pela reunião na unidade absoluta, se coloca sobre seus próprios pés e se move autonomamente em seu próprio âmbito"? ?

O homem aqui se refere a si e se prende a fins particulares, o que significa que, para a arte, cuja finalidade é apresentar a unidade imediata entre interior e exterior, esses "lados tornam-se formais", pois o que é substancialmente objetivo se mostra separado da subjetividade. O que é ético e substancial é preterido pelo fim particular subjetivo, que quando quer realizar tal fim entra em colisão com os outros fins particulares. Na "Filosofia do direito" Hegel identifica a luta pela realização desses fins subjetivos como o sistema da eticidade perdida nos seus extremos. ${ }^{8}$ A forma de arte romântica apresenta essa luta por meio do que Hegel nomeia como a 'autonomia formal dos particulares individuais', na qual o que conta é o mundo particular, o querer e os fins individuais. "Desta espécie", afirma Hegel, "são principalmente os caracteres de Shakespeare, nos quais a firmeza férrea e unilateralidade constituem o aspecto particularmente admirável".

A sociedade civil burguesa hegeliana, por um lado, é o lugar das "necessidades naturais e do arbítrio" e, assim, da particularidade e da contingência. Por outro, todavia, porque essas mesmas carências devem considerar uma relação entre as demais carências e o seu suprimento, ela já porta, na própria esfera da particularidade, segundo Hegel, certa universalidade, constituída por meio dessa relação negativa entre os particulares. A satisfação das carências subjetivas e a realização dos arbítrios particulares se dão na necessária conexão com os demais arbítrios e com as outras formas particulares de satisfação das carências. Hegel afirma que, "pela sua relação aos outros, o fim particular se dá na forma da universalidade e se satisfaz enquanto, ao mesmo tempo, satisfaz conjuntamente o bem-próprio de outrem". ${ }^{10}$

Essa mediação entre o particular e o universal ainda é insuficiente e denunciada em sua indeterminação por Hegel, pois é uma particularidade mediada apenas na esfera das carências, portanto, do particular. Há uma mediação superior e mais determinada, na qual a ação individual pode ser justificada. A unidade entre o indivíduo das paixões da sociedade civil burguesa e o cidadão do Estado é realizada, em sua efetividade, pela mediação deste

7 Hegel, 2000a, p. 309.

8 Cf. Hegel, 2000b, § 184.

9 Hegel, 2000a, p. 313.

10 Hegel, 2000b, § 182. 
último, na qual a ação individual se apresenta legitimamente justificada apenas e na medida em que é uma ação que tem como fim último a universalidade política incorporada pelo Estado. ${ }^{11}$

\section{O princípio lírico da modernidade e o romance como a forma poética da modernidade}

Retomando uma determinação conceitual da "Estética" hegeliana, na "Teoria do romance" Lukács entende a forma romance, sob a perspectiva da economia dos gêneros poéticos, como um desenvolvimento interno da epopeia. Ele compreende, também a partir de Hegel, a unidade entre as duas grandes formas épicas, o romance e a epopeia, e o solo histórico no qual tais formas são configuradas. ${ }^{12}$ Essas duas configurações poéticas são desdobramentos internos de uma mesma unidade: entre forma artística e conteúdo históricosocial, determinações que, assim, apoderam-se do ponto essencial do esforço conceitual da "Estética" hegeliana e estruturam o conjunto da exposição da "Teoria do romance". Se, de um lado, Lukács concebe a forma artísticopoética a partir "dos dados histórico-filosóficos com que [esta] se depara para a configuração", ${ }^{13}$ concepção que o vincula diretamente à "Estética" hegeliana, por outro, ele se distancia da identidade apresentada por Hegel entre a liberdade plenamente desenvolvida e a época moderna, identidade cuja totalidade e verdade apenas o discurso filosófico é capaz de fornecer. Afirma Hegel que a ciência filosófica "é precisamente o fundamento do racional, [...] é a apreensão (Erfassen) do presente e do efetivo (wirklich)" ${ }^{14} \mathrm{O}$ corte fundamental com o pensamento hegeliano é determinado pela concepção do autor da "Teoria do romance" sobre a modernidade, pois, ao invés de concebêla como cumprimento da liberdade do espírito, tal como a pensa Hegel, a compreende como a configuração acabada da dissonância, da fragmentação, da separação.

A divergência crucial entre Lukács e Hegel é que, para este, a época moderna alcança sua verdade e totalidade na forma Estado, que suspende o momento de antagonismo da sociedade civil burguesa, enquanto para o autor húngaro, ao contrário, a época moderna é determinada pela separação do indivíduo em relação às estruturas sociais, conceito lukacsiano para se referir

11 Cf. Hegel, 1998, § 258.

12 Cf. Lukács, 2000, p. 55

13 Idem.

14 Hegel, 1959, p. 13. Tradução cotejada com o original alemão e levemente modificada. 
também ao Estado. A dissonância entre "eu e mundo" que demarca a "solidão" do homem da lírica ou o sujeito "fragmentado" corresponde ao momento da sociedade civil burguesa hegeliana e é, para Lukács, o que determina a "verdade" da experiência moderna, sendo tal separação o fundamento do mundo no qual se produz o romance como forma.

Hegel pensa a lírica como a mais determinada e desenvolvida das formas de arte poética, porque ela é a expressão artística da consolidação moderna do princípio da subjetividade. A lírica, segundo a concepção de Hegel, necessita, para o seu desenvolvimento, de uma época na qual as relações sociais sejam mediadas pelo Estado. Para a consolidação da lírica, é necessária uma organização social que tenha um desenvolvimento material e espiritual capaz de permitir ao homem voltar-se primordialmente para o seu interior e sentimento, nos quais a forma da particularidade é o princípio vetor. ${ }^{15}$

Segundo Hegel, na época moderna já não se exige uma arte alicerçada na objetividade da coisa, ela não tem que fazer a coisa aparecer em seu pleno desenvolvimento, como ocorre na epopeia, que narra a ação individual do herói inserido na totalidade orgânica de um mundo fechado em si mesmo, ou como no drama, que tem ainda de apresentar a ação dos heróis, que assumem um pathos universal do todo, que colidem entre si. No drama, "assim como no épico [que exige a objetividade da coisa], é desdobrada diante de nós uma ação em sua luta e desenlace, potências espirituais se expressam e entram em conflito [... $]{ }^{1} .{ }^{16} \mathrm{Em}$ ambos os gêneros, a objetividade do objeto ou a narração objetiva da ação estão presentes. Na lírica, ao contrário, é a subjetividade, a interioridade que atua como principio configurador. É assim que, conforme Hegel,

a arte da poesia lírica avança certamente para situações determinadas, no interior das quais permanece facultado ao sujeito lírico introduzir uma grande multiplicidade do conteúdo em seu sentimento e reflexão; todavia, neste gênero, é sempre a forma do interior que fornece o tipo fundamental e já desse modo exclui de si a ampla intuitibilidade da realidade exterior. ${ }^{17}$

Na modernidade, assim, não há mais apenas um número reduzido de matéria artística, tal como acontece na epopeia, que deve apresentar

15 "Se, a saber, exigimos para a época do florescimento da epopeia propriamente dita um estado nacional ainda não desenvolvido no todo, ainda não amadurecido para a prosa da efetividade, para a lírica, ao contrário, tais épocas são particularmente propícias, as quais já produziram uma ordem tornada acabada em maior ou menor grau das relações da vida, pois só nesses dias o homem singular se reflete em si mesmo perante este mundo exterior e se isola para seu interior para uma totalidade autônoma do sentir e do representar" (Hegel, 2004, p. 167).

16 Ibidem, p. 85.

17 Ibidem, p. 123. 
objetivamente a individualidade autônoma do herói em unidade com o destino da comunidade, ou no drama que, igualmente, tem que mostrar a unidade entre o pathos individual do herói e a substância universal ética. ${ }^{18} \mathrm{Na}$ lírica, a matéria se apresenta de forma múltipla porque o homem não se encontra mais naquela unidade imediata com a objetividade do Estado ou da comunidade, mas, ao contrário, encontra-se numa vida prosaica desenvolvida, em que tal unidade é mediada pela autonomia da subjetividade. Afirma Hegel que

[...] o sujeito singular e justamente com isso a singularização da situação e dos objetos, bem como do modo em que o ânimo com seu juízo subjetivo, sua alegria, seu maravilhamento, sua dor e seu sentir leva em geral a si à consciência [o conteúdo da obra de arte lírica]. Por meio deste princípio que reside no lírico, da particularização [Besonderung], da particularidade [Partikularität] e da singularidade, o conteúdo pode ser da maior multiplicidade e atingir todas as direções da vida nacional, todavia, com a diferença essencial de que, se a epopeia desdobra em uma única e mesma obra o espírito do povo em seu ato e condicionalidade efetivos, o conteúdo mais determinado do poema lírico se limita a algum particular [...]. ${ }^{19}$

Nessa esfera, o homem possui o direito de olhar para várias direções, para onde o ânimo interior desejar. Pela multiplicidade de matéria e de temas, que estão alicerçados na multiplicidade de experiências particulares individuais próprias à sociedade civil burguesa, a lírica é considerada por Hegel como a arte poética mais apropriada para expressar o mundo dessas relações.

Na sua apreciação sobre a lírica na "Teoria do Romance”, Lukács concorda com Hegel, em princípio, quanto ao estatuto da lírica na modernidade, ou seja, quanto à sua determinação como expressão do "homem solitário" e fragmentado do "mundo contingente" da sociedade civil burguesa. Aapreciação de Hegel sobre as formas artísticas na modernidade - e por isso também sobre a lírica - é inseparável do seu juízo acerca do limite da arte como exposição da verdade. É por isso que para ele se, por um lado, a lírica é a expressão artística própria da modernidade, por outro, ela não é capaz de configurar e apresentar a totalidade e unidade concreta desse mesmo mundo moderno, ou seja, ela é apenas uma verdade particular da modernidade ou, em outras palavras, a lírica é a verdade da arte moderna e não a exposição da verdade da própria modernidade. Isso ocorre porque ela permanece unilateralmente imersa na forma da subjetividade, na vida privada, vida dos quereres individuais, que se situam na vivência limitada à esfera da sociedade civil burguesa. 
A lírica é, também para Lukács, a expressão artística da interioridade. Se ela, afinal, é "a linguagem do homem absolutamente solitário [...], monológic[o]", ${ }^{20}$ é que para ele, como para Hegel, a modernidade engendra esse lirismo como princípio fundamental. Se nos reportarmos ao momento da "Teoria do romance" no qual o seu autor traça a tipologia das formas romanescas, encontraremos Lukács, ao referir-se ao "romantismo da desilusão", esclarecendo-nos acerca desse lirismo do indivíduo solitário em sua oposição ao mundo existente. O encarceramento em si mesmo do herói do romance da desilusão, a ausência de ação no mundo, é assinalado por Lukács como indicador da solidão lírica que determina a atividade narradora ou o poetizar romântico. Diz ele que a postura romântica do poeta e, manifestamente, do herói do romance da desilusão, é de

uma sofreguidão excessiva e exorbitante pelo dever ser em oposição à vida e uma
percepção desesperada da inutilidade dessa aspiração; uma utopia que, desde o início,
sofre de consciência pesada e tem certeza da derrota. E o decisivo nessa certeza é o
seu vínculo indissolúvel com a consciência moral, a evidência de que o fracasso é
uma consequência necessária de sua própria estrutura interna, de que ela, em sua
melhor essência e em seu valor supremo está fadada à morte. Eis porque a postura
tanto em face do herói quanto do mundo externo é lírica $\left[\ldots . . .{ }^{21}\right.$

Para bem compreender a relação entre romance e lirismo e os problemas que essa relação comporta no que se refere à leitura da modernidade, é preciso antes lembrar que o romance, para Lukács como para Hegel, não pertence ao gênero lírico, mas ao épico. A divisão dos gêneros é o momento mais formal tanto para o autor da "Estética" quanto para o da "Teoria do romance". Essa formalidade apenas se deixa explicar quando descemos ao conteúdo que determina a forma paradigmática de cada um desses gêneros em sua relação com o desenvolvimento histórico. Se lírica e épica se entrecruzam e se atravessam na poética da modernidade, no romance, isso ocorre porque os gêneros são apenas as indicações formais mais abstratas da relação poética entre o "eu e o mundo". Assim, o gênero épico demarca, para ambos, uma conexão necessária entre vida e sentido, para usar os termos de Lukács, ou entre o indivíduo e a totalidade, para falar como Hegel, delimitando, desse modo, uma relação de imanência da totalidade ao eu. Por seu turno, o drama, para Hegel, ou a tragédia - a única forma dramática examinada por Lukács demarca uma quebra reflexiva dessa relação de imanência que, entretanto, não 
separa inteiramente o eu da totalidade. Se no drama a relação de imanência da epopeia aparece cindida, o desenlace trágico deve ainda repor a unidade entre o eu e a substância, o sentido. A lírica é a forma, na qual a cisão encontrase sob o signo da não conciliação, da separação consumada, cisão que na tragédia se apresenta reconciliada, reposta.

Trata-se, para ambos os autores, de pensar os gêneros e seus desenvolvimentos poético-formais, isto é, de pensá-los a partir da imersão do poetizar em formas históricas, que, antes de separá-los, evidenciam a articulação desse momento de autonomia formal dos gêneros à sua aderência ao conteúdo histórico a partir do qual a configuração poética se dá em cada caso. Se a relação entre forma e conteúdo pressuposta na articulação hegeliana dos gêneros aponta, de um lado, para a conexão da épica com a experiência arcaica grega sob a forma mais determinada da epopeia e, de outro, para a conexão do lirismo com a modernidade, essa conexão é regida pelo conteúdo de tais experiências. Este conteúdo é o que se encontra desenvolvido em cada um desses momentos históricos com base em suas diferentes determinações, em seus distintos princípios. O conteúdo é o que garante a correspondência entre a epopeia e a experiência imediata de imersão na totalidade experimentada pelos gregos, assim como a correlação entre a lírica, como separação entre eu e mundo, e o princípio da subjetividade que a determina. O fato de que o conteúdo lírico da experiência moderna seja, assim, oposto à aderência imediata à totalidade, própria à forma verdadeira da épica, a epopeia, bem como à experiência que lhe fundamenta, não significa que os gêneros poéticos não se apresentem, por isso, em todas as experiências humanas do poetizar, embora apareçam sempre de forma subordinada a essa determinação mais geral do conteúdo.

É assim que os gêneros poéticos se apresentam como determinações mais abstratas ou formais, ganhando sua verdade ou concreção a partir da relação com a determinação do conteúdo espiritual mais geral no seio da qual cada experiência poética acontece. Desse modo, nas várias experiências poéticas do espírito, até mesmo naquelas que Hegel designa como préartísticas (Vorkunst), ${ }^{22}$ como ocorre, por exemplo, na lírica oriental, os gêneros se apresentam baseados nessa subordinação ao desenvolvimento mais universal do conteúdo. É essa dialética da forma e do conteúdo que nos explica a afirmação, de Lukács e de Hegel, do romance como a forma poética da épica moderna. Isso significa dizer que esse gênero épico, que tem seu paradigma incontestável na epopeia homérica, aparece, em sua configuração 
moderna, atravessado pelo lirismo, pelo princípio da subjetividade que lhe é historicamente subjacente, ou seja, que é a sua determinação de conteúdo.

O romance, cuja exigência épica é a da configuração extensiva da vida do momento histórico no qual ele é produzido, possui, assim, na sua arquitetônica, formada pelo artista, bem como na sua constituição interna, o princípio vetor que determina a experiência moderna, a subjetividade e a interioridade líricas. As formas artísticas produzidas na modernidade ou em épocas imediatamente anteriores e de transição, mas que já apontam para uma consolidação da subjetividade, aparecem, desse modo, determinadas por essa interioridade lírica. Eis porque Lukács apresenta, por exemplo, o “caráter puramente reflexivo [da] interioridade"23 de um Dom Quixote, buscando apontar que, mesmo agindo no mundo em razão da solidão - do lirismo -, sua ação limita-se a permanecer referida somente à interioridade. Ou ainda, quando afirma a distância de Dante do lirismo, reconhece a presença deste na epopeia dantesca quando esta é comparada à epopeia homérica. Diz Lukács que "tampouco os versos de Dante são líricos, embora mais líricos que os de Homero: eles condensam e unificam o tom de balada em epopeia". ${ }^{24}$

Essas considerações sobre as relações entre lírica e romance têm o sentido de demarcar a especificidade da leitura de Lukács acerca da modernidade, e isso tanto em sua consonância quanto em sua diferença com Hegel. Trata-se de pontuar que a verdade da modernidade, para Lukács, confina-se naquilo que Hegel designa como a esfera da sociedade civil burguesa, em razão do que aparece uma importante distinção estética - que é alicerçada na discordância política lukacsiana da forma Estado como efetivação da liberdade - entre eles quanto à expressão artística por excelência da modernidade. Para Hegel, é a lírica a verdadeira expressão artística da modernidade, pois a arte se limita, como vimos, a configurar o que é particular, nisso não expondo a unidade e totalidade objetivas, que o romance deve apresentar enquanto parte do gênero épico. Para Lukács, é o romance a verdadeira exposição artística do mundo moderno fragmentado e de sua única unidade possível: a unidade formal, abstrata. Isso ocorre porque Lukács discorda que a época moderna possua uma "verdade" superior - que para Hegel é o Estado, do lado das instituições políticas e a filosofia, do lado da exposição da verdade - que suspenda a liberdade limitada do homem solitário da lírica e, assim, constitua uma totalidade real de sentido. Se existe uma suspensão do homem da lírica - e o romance é, para Lukács, a busca não realizada dessa suspensão -, essa 
se move ainda no próprio terreno da lírica, porque a totalidade configurada pela forma do romance é ela mesma formal, não efetiva, porque ela é uma totalidade apenas artificial e criada em oposição à fragmentação da realidade. "A arte", afirma Lukács, "tornou-se independente [selbständigkeit]: ela não é mais uma cópia, pois todos os modelos desapareceram; é uma totalidade criada [erschaffene Totalität], pois a unidade natural das esferas metafísicas foi rompida para sempre". ${ }^{25}$

Essa artificialidade é o que denuncia a sua consonância ao princípio da subjetividade que fundamenta a lírica. O romance, para Lukács, é assim, a configuração de um mundo no qual a totalidade não está mais dada de maneira evidente $^{26}$ e por isso ele afirma que a totalidade e a unidade desse mundo são criadas a partir da subjetividade do artista, o que repõe o princípio lírico no interior da construção do romance. Essa determinação do romance como totalidade artificial - que em Hegel demarca a verdade do romance, mas não da modernidade - expressa a recusa de Lukács em pensar a experiência moderna como a expressão acabada da liberdade, na qual a forma Estado garante a coesão do todo. Para Lukács, ao contrário, a produção e "a criação das formas é a mais profunda confirmação que se pode pensar da existência da dissonância". ${ }^{27}$ Porque Lukács não pensa a modernidade como realização da unidade entre vida e sentido, que a forma romance é aquela que expõe a verdade da experiência moderna, pois a concebe como a experiência da dissonância, aquela mesma que em Hegel designa a esfera mais limitada da sociedade civil burguesa, na qual a subjetividade tenta ir além de seu próprio isolamento, ainda que apenas formalmente.

A formalidade própria à liberdade na esfera da sociedade civil burguesa apresentada por Hegel se associa à formalidade da totalidade apontada por Lukács como própria à forma do romance. Essa identidade entre romance e sociedade civil burguesa, aliás, já é apontada pelo próprio Hegel quando este limita a arte moderna à exposição da particularidade. Se, para Hegel, o desenvolvimento real dessa "formalidade" subjetiva impele à unidade no Estado, impulso que é o mesmo que determina a possibilidade de suspensão da particularidade no todo do Estado, na "Teoria do romance" é também essa formalidade o que aponta, embora não realize efetivamente, para a possibilidade contida na subjetividade em ir além do próprio mundo do romance. Afinal, se o romance realiza uma ruptura com a lírica que faz com 
que o herói da moderna épica se situe sempre na busca por transcender a solidão própria ao eu lírico - aquilo que possibilita ao romance a configuração artificial da totalidade -, essa característica é a expressão da contradição na qual o eu fragmentado da experiência moderna se encontra em dissonância com o mundo fragmentado que o aprisiona. Ora, mas essa contradição exposta no romance e nele apenas superada formalmente é o desenvolvimento da contradição posta no e pelo eu lírico.

Ao contrário da imagem reconciliada oferecida por Hegel - embora tal reconciliação não seja para Hegel artística, mas política e conceitual -, Lukács, por um lado, apreende o romance como a exposição do desenvolvimento histórico real da individualidade moderna que, longe de deixar de ser problemática por meio de sua inserção no Estado, permanece contraditória, só resolvendo tal contradição formalmente na obra. Por outro lado, não obstante esse desenvolvimento formal da subjetividade expresso no romance, ele é, mesmo nessa formalidade, aquilo que já possibilita ou fornece o "pano de fundo" para uma possível superação desse mundo fragmentário que ele expõe.

Em vários momentos da "Teoria do romance", Lukács menciona essa potência subversiva da subjetividade exposta no romance, que traz consigo a possibilidade do rompimento com a pura formalidade da época moderna, embora ele próprio, o romance, não consiga transcender essa época histórica da qual é a expressão. Lukács caracteriza, por exemplo, a leveza da grande épica - que inclui a epopeia e o romance - como uma possibilidade do rompimento dos "grilhões" que prendem o homem "ao solo". A grande épica arcaica homérica não é e não pode ser um rompimento do homem dos grilhões que o prendem à comunidade "ao solo", ${ }^{28}$ mas, ao contrário, ela é a confirmação e imersão total do homem nos valores dessa cultura. De acordo com isso, ao falar sobre a leveza da épica como a recusa de um mundo que mantém o homem cativo, Lukács tem em mente o romance, no qual a possibilidade de recusa do mundo, que ele próprio configura e supõe, está dada. Não se trata de afirmar que o romance transcende a fragmentação da lírica, mas que ele contém essa potência da subjetividade de ir além do seu próprio mundo. A "leveza", impressa pela épica moderna, aponta para a afirmação dessa potência subjetiva, ausente no mundo da epopeia homérica. É preciso sempre acrescentar que, para Lukács, no romance, a subjetividade e todo esforço de transcendência da separação entre o "eu e o mundo" por ela experimentado apenas podem produzir a unidade como uma formalidade, 
uma vez que a separação ou o lirismo permanece ainda como sua base de sustentação. Lukács destaca a impossibilidade real de uma experiência com o sentido no interior das relações prosaicas burguesas, não porque o sentido esteja presente para além da fragmentação da sociedade civil burguesa nas estruturas éticas do Estado, como pensa Hegel, mas por que tal experiência se constitui, como experiência isolada e subjetiva, na forma própria do sentido no mundo moderno fragmentado.

\section{Referências}

HEGEL, G. W. F. "Werke” [in 20 Bänden]. Frankfurt am Main: Suhrkamp, 1986. . "Cursos de Estética". Vol. I. Tradução de Marco Aurélio Werle. $2^{\mathrm{a}}$ ed. rev. São Paulo: EDUSP, 2001.

. "Cursos de estética". Vol. II. Tradução de Marco Aurélio Werle. São Paulo: EDUSP, 2000a.

. "Cursos de estética". Vol. IV. Tradução de Marco Aurélio Werle e Oliver Tolle. São Paulo: EDUSP, 2004.

. "Enciclopédia das ciências filosóficas". Vol. III, Filosofia do Espírito. Tradução de Paulo Meneses. São Paulo: Loyola, 1995.

. "Lecciones sobre la filosofía de la historia Universal". Tradução de José Gaos. $4^{\mathrm{a}}$ ed. Madri: Alianza Editorial, 1989.

. "Linhas fundamentais da filosofia do direito". Tradução de Marcos Lutz Müller. Campinas: IFCH/UNICAMP, 1998. Terceira Parte: Eticidade; Terceira Seção: O Estado.

Tradução de Marcos Lutz Müller. Campinas: IFCH/UNICAMP, 2000b.

. "Princípios da filosofia do direito". Tradução de Orlando Vitorino. Lisboa: Guimarães Editores, 1959.

LUKÁCS, G. "Die Theorie des Romans. Ein Geschichts-philosophischer Versuch über die Formen der Grossen Epik". München: DTV, 1994.

. "A teoria do romance: um ensaio histórico-filosófico sobre as formas da grande épica". Tradução, posfácio e notas de José Marcos Mariani de Macedo. São Paulo: Duas Cidades; Ed. 34, 2000. 